\title{
Perception and role of standards in the world of biomimetics
}

\section{Dr. Kristina Wanieck}

Professor, Arbeitsgruppe Bionik (Working Group Biomimetics), Technische Hochschule Deggendorf (Deggendorf Institute of Technology), Freyung, Germany (Orcid:0000-0002-2280-1971) (corresponding author: kristina.wanieck@th-deg.de)

\section{Dr. Heike Beismann}

Professor, Lehrgebiet Biologie und Bionik (Teaching Area Biology and Biomimetics), Fachbereich Maschinenbau (Department of Mechanical Engineering), Westfälische Hochschule (Westphalian University of Applied Sciences), Bocholt, Germany (Orcid:0000-0002-6360-0471)

Biomimetics is the interdisciplinary co-operation of various scientific disciplines and fields of innovation, and it aims to solve practical problems using biological models. Biomimetic research and its fields of application are manifold, and the community is made up of a wide range of disciplines, from biologists and engineers to designers. Guidelines and standards can build a common ground for understanding of the field, communication across disciplines, present and future projects and implementation of biomimetic knowledge. Since 2015, three international standards have been published and defined terms and definitions, as well as specific applications. The scientific literature and patents in several databases were searched for citations of the published standards. Standards or technical guidelines on biomimetics are represented both in the scientific literature and in patents. However, taking into account the increasing number of publications in biomimetics, the number of publications (52) citing the international standards is low. This shows that the perception of technical rules is still underrepresented in the academic field. Greater awareness and acceptance of the importance of standards for quality assurance even in the academic environment is discussed, and active participation in the corresponding International Organization for Standardization committee on biomimetics is asked for.

\section{Introduction}

The International Organization for Standardization (ISO) was founded with the idea of answering a fundamental question: 'what's the best way of doing this?' measures, and over the past 50 years, it has developed a huge number of more than 23000 ISO standards that touch almost all aspects of daily life and work. International standards mean that consumers can have confidence that their products are safe, reliable and of good quality. Regulators and governments count on ISO standards to help develop better regulation, knowing that they have a sound basis thanks to the involvement of experts. ${ }^{1}$ Nonetheless, the application of standards is voluntary. Standards become legally binding only when laws or regulations refer to them. Besides, contractual partners can also make the application of standards binding in agreements. If this is not the case, standards can nevertheless serve as a decision-making aid in the event of a dispute - for example, in liability proceedings. Courts refer to standards and technical rules in proceedings in order to assess whether the manufacturer has observed the generally accepted rules of technology. To clarify whether a product has a defect, the judges can refer to relevant standards. Based on these standards, they derive how a product should be designed in the opinion of uninvolved experts. If the relevant standards are not complied with, the seller or manufacturer must prove in some other way that the product meets the requirements customary in the trade. In the process, the user of the standard has the decisive advantage that, as a result of compliance with the standard, they can claim to have followed the generally accepted rules of technology. Therefore, compliance with standards provides a certain legal certainty for producers and consumers. ${ }^{2}$
Technical Committee 266 Biomimetics of ISO (ISO/TC 266) was founded in 2012 and is responsible for all standardisation work concerning biomimetics. In this committee, experts from all over the globe work on standards with the motivation that they are expected to contribute to the overall acceptance of biomimetic new or optimised products. ${ }^{3}$ Biomimetic products have the potential to boost important aspects such as sustainability, business opportunities or legal issues, all for the benefit of the producers of the product and their respective customers. ${ }^{3}$ If these benefits are widely accepted through the means of standards, then companies may find easier access to new biomimetic products and new markets based on these products and can thus derive appropriate long-term business strategies. In cases where no products but methods are involved, standards give rise to a clear distinction of what biomimetics includes and what it does not include. ${ }^{3}$

The starting point was a set of Verein Deutscher Ingenieure (VDI) guidelines (VDI 6220 to VDI 6226) developed in the Fachbereich Bionik (Biomimetics Group) of the VDI Society Technologies of Life Sciences. VDI is the Association of German Engineers, which provides engineers with a professional base, network and guidelines. The bilingual guidelines

- VDI 6220 Part 1, 'Biomimetics - conception and strategy differences between biomimetic and conventional methods/ products 4

- VDI 6223 Part 1, 'Biomimetics - biomimetic materials, structures and components, 5

- VDI 6224 Part 2, 'Biomimetic optimization - application of biological growth laws for the structure-mechanical optimization of technical components, ${ }^{6}$ 
were particularly relevant for the definitions of terms and industrial applications in the field of biomimetics. They were therefore selected to serve as a basis for the preparation of international standards. By now, three ISO standards are published:

- ISO 18458, 'Biomimetics - terminology, concepts and methodology, 7

- ISO 18457, 'Biomimetics - biomimetic materials, structures and components, 8

- ISO 18459, 'Biomimetics - biomimetic structural optimization'.9

ISO $18458^{7}$ defines relevant terms connected with biomimetics and gives answers to the question what biomimetics is and when a product or process is 'biomimetic'. ISO $18457^{8}$ deals with biomimetics in relation to the development of materials, structures, surfaces, components and manufacturing technologies. Finally, ISO $18459^{9}$ describes the functions and applications of biomimetic structural optimisation methods. ${ }^{10}$

Therefore, to answer the aforementioned question 'what is the best way of doing this ${ }^{1}$ is for biomimetic structural optimisation to do it in the way that ISO 18459 describes it. To answer the question if a product is biomimetic or not, ISO 18458 serves with three criteria to solve this, and ISO 18457 helps decide what kind of possibilities biomimetics offers in the field of materials. This is the intention of ISO/TC 266 and is in line with ISO standards in general and how they should serve society.

As mentioned before, the application of standards in general, and biomimetics in particular, is voluntary, but they help doing biomimetics in practice and serve as a reliable foundation for such development processes. ${ }^{11}$ With this paper, the authors want to find out more about the perception of standards on biomimetics in the engineering and scientific world. To assess the impact of ISO standards on biomimetics so far, the study analyses scientific publications and patents and the way in which the standards are cited therein. Furthermore, insights into the perception and usage of ISO standards on biomimetics might also help learn how to improve the dissemination of and communication about ISO standards on biomimetics. Table 1 summarises the different guidelines and documents that have been developed and were of interest in this research. It is shown with these 13 documents that the field of biomimetics is quite well presented in guidelines and standards. Nevertheless, it is expected that future topics will arise and that the list of documents may be expanded.

\section{Methods}

\subsection{Literature research and databases}

To ensure the most comprehensive research possible, databases were selected that are comprehensively oriented towards science and engineering. Databases included in the research were Web of Science (December 2019), IEEE Xplore (December 2019) and Tema (February 2020). Additionally, Google Scholar (December 2019) was used to complement peerreviewed articles with other types of scientific documents, such as master's theses or project theses.

Web of Science enables parallel and interdisciplinary research in an extensive database under one search interface (CrossSearch). The database can be accessed by way of http://www. webofknowledge.com. In contrast to IEEE Xplore, Web of

Table 1. List of international standards and VDI guidelines on biomimetics

Document number

ISO $18457^{8}$
ISO $18458^{7}$
ISO $18459^{9}$

VDI 6220 Part $1^{4}$ revised draft

VDI 6220 Part $1^{12}$

VDI 6221 Part $1^{13}$

VDI 6222 Part $1^{14}$

VDI 6223 Part $1^{5}$

VDI 6224 Part $1^{15}$

VDI 6224 Part $2^{6}$

withdrawn

VDI 6224 Part $3^{16}$

VDI 6225 Part $1^{17}$

VDI 6226 Part $1^{18}$

\section{Title}

Published

Biomimetics - biomimetic materials, structures and components

Biomimetics - terminology, concepts and methodology

Biomimetics - biomimetic structural optimization

September 2016

May 2015

May 2015

Biomimetics - fundamentals, conception and strategy

July 2019

Biomimetics - conception and strategy differences between biomimetic and conventional methods/products

Biomimetics - biomimetic surfaces

Biomimetics - bionic robots

Biomimetics - biomimetic materials, structures and components

December 2012

September 2013

November 2013

June 2013

Biomimetic optimization - application of evolutionary algorithms

June 2012

Biomimetic optimization - application of biological growth laws for the structure-mechanical

August 2012

optimization of technical components

Biomimetics - integrated product development process for biomimetic optimization

September 2017

Biomimetics - biomimetic information processing

Biomimetics - architecture, civil engineering, industrial design - basic principles

ISO, International Organization for Standardization; VDI, Verein Deutscher Ingenieure e.V. (Association of German Engineers)

A VDI guideline can encompass various parts. A new guideline is usually classified as Part 1. Individual parts can be revised or withdrawn. The revised version needs to pass an evaluation process, and it is classified as a draft until acceptance. Older or withdrawn versions of a VDI guideline are still available; however, the newest version is recommended to be referred to 
Science is a publisher-independent global database. Web of Science contains over 21100 peer-reviewed scientific journals, including open-access journals in over 250 scientific fields. Conference papers and books are also included. Furthermore, Web of Science is linked to Google Scholar. Google Scholar results include the times cited counts and direct links to the Web of Science Core Collection.

The IEEE Xplore database can be accessed at https:// ieeexplore.ieee.org. It allows discovery and access to scientific and technical content published by the Institute of Electrical and Electronics Engineers (IEEE) or its publication partners. In total, more than 195 journals, 1800 conferences, 2400 books, 9000 standards and nearly 500 training courses are listed, with more than 5 million items to search. Nearly 20000 new documents are added each month. Thematically, IEEE Xplore covers in particular the electrical-engineering- and computer-related fields, but also general engineering topics, bioengineering and robotics are covered. Since the VDI guidelines VDI 6222 Part 1 (robotics) and VDI 6225 Part 1 (information processing) belong to these areas, IEEE Xplore was included.

Tema is a database owned by WTI-Frankfurt-digital GmbH covering technology and management and is available at https:/tecfinder.wtifrankfurt.de/tecfinder. The database bundles information from German and international scientific and applied literature. Thematically, this database is clearly designed for engineers and covers the following topics, among others: mechanical and plant engineering, electrical and electronic engineering, materials science and medical technology. The database was included in the literature research, as the basis for the ISO standards are VDI guidelines, which were developed in Germany.

\subsection{Patent research and databases}

Four databases for patents were used:

- Depatisnet on 15 October 2019, for full-text searches in German documents (https://www.dpma.de/recherche/depatisnet/)

- Espacenet on 15 October 2019, for full-text searches in German, English and French documents (https:// worldwide.espacenet.com/)

- FreePatentsOnline on 7 October 2019 (http:// www.freepatentsonline.com/)

- Patentscope on 16 October 2019 (https://patentscope.wipo.int/ search/en/search.jsf).

\subsection{Keywords}

The keywords 'ISO 18457', 'ISO 18458' and 'ISO 18459' for ISO standards were used, covering all published ISO standards for biomimetics. Additionally, VDI guidelines were included, for they are published bilingual in German and English, with the keywords 'VDI 6220', 'VDI 6221', 'VDI 6222', 'VDI 6223', 'VDI 6224', 'VDI 6225' and 'VDI 6226', covering all published VDI guidelines connected to biomimetics. No distinction was made between the different parts of a VDI guideline - for example, VDI 6224 Parts
1-3 - and thus all optimisation standards were considered together. Keywords and search strings were adapted to the syntax of the respective search engines or databases.

\subsection{Categories}

The resulting articles were sorted according to the standards or technical rules cited - that is, assigned to a category indicating which standard or VDI guideline was referenced. This corresponds to the keywords used for the databases (see above) for full-text search.

Moreover, thematic categories were created that provide information on the context in which the standard or VDI guideline was cited or used.

- 'Terminology' identifies documents in which the standard or VDI guideline is cited in order to refer to the definition laid down in the standard or VDI guideline in the further course of the document. The authors use the standards to refer to a specified language and apply the terminology according to the standards.

- 'Approach' denotes documents that use the procedure described in the standards (bottom-up, top-down) or use the standards to refer to these procedures.

- 'Application' categorises documents that use a method described in the standards and apply the terminology and methodology according to the specifications of the VDI guideline or the ISO standard. This essentially identifies documents that describe a product development and use the specified method for this purpose.

- 'Evaluation' contains documents that have carried out an examination of a product to determine whether it is a biomimetic product according to the three criteria from the standards. Besides, documents that have carried out an evaluation of a biomimetic product in a different way were also placed here.

- 'State of the art' denotes a category of documents that have cited the standards to represent the general state of the art that the authors intend to follow in the further course of their document.

\section{Results}

Altogether 52 documents were found. This includes patents $(n=$ $3)$ and articles $(n=49)$, including peer-reviewed research papers and further types of scientific articles - for example, project studies and conference papers - that were listed by the databases. Several standards can be cited in one document; therefore, the sum of citations counted for individual standards does not have to correspond to the number of the total documents. For further analysis, patents and articles will be considered separately.

\subsection{Literature databases}

A total of 49 articles cite at least one of the standards (ISO) or one of the VDI guidelines on biomimetics as listed in Table S1 in the online supplementary material. The overall frequency of citations is 75 . Out of the 75 identified citations, 74 could be classified by the thematic categories. One could not be classified due to limited access. The international standards (ISO) are cited significantly more often (59 
times in 43 articles), compared with the bilingual VDI guidelines (16 times in nine articles). Table S1 in the online supplementary material summarises all 49 identified articles sorted by year and shows the respective citations of ISO standards and VDI guidelines an can be found as sources $19-65$ in the references.

Of the ISO standards, the standard on terminology (ISO 18458), with 37 articles, is cited significantly more frequently than the standards on biomimetic structural optimisation (ISO 18459), with 15 articles, and the standard on biomimetic materials (ISO 18457), with seven articles. Again, the sum of articles does not have to correspond to the total number of articles, due to the multiple citations in one article (Figure 1).

Of the VDI guidelines, VDI 6220 (terminology) is also quoted more frequently (in seven articles) than the other VDI guidelines, which are mentioned in only one to three articles. VDI 6226 is the only guideline that was not cited at all.

Articles use the standards on biomimetics in different ways, which was analysed by defining the respective categories mentioned earlier. The most common use of standards on biomimetics is to use the definitions laid down there for one's own work. The terminology according to ISO 18458 or VDI 6220 Part 1 is cited and thus defined for one's own language use. This is the case for 36 articles (Figure 2). For other reasons, the standards on biomimetics are cited less frequently. In 14 articles, reference is made to the approach within a biomimetic development process. In eight articles, the use of a biomimetic method is declared (application) or the standards are used to explain the state of the art (seven articles). Moreover, in only five articles, a standard is used for clarification with regard to the evaluation of a biomimetic product.

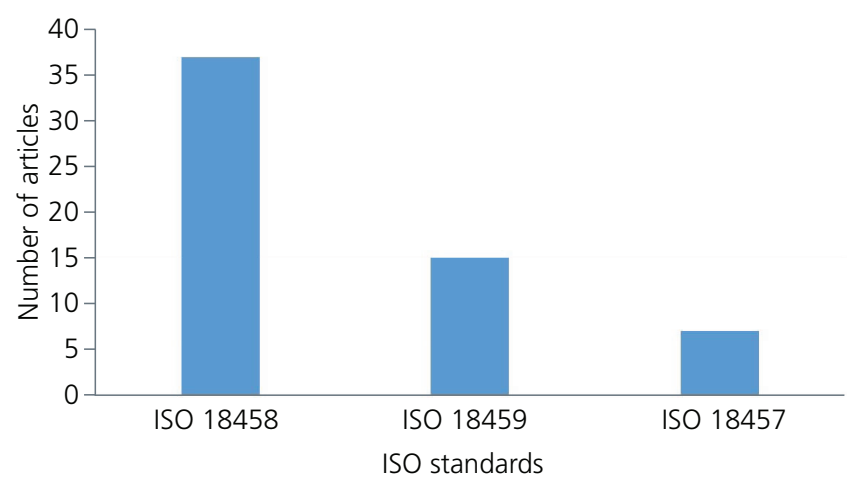

Figure 1. Number of articles citing the ISO standards on biomimetics. The ISO standards 18458 and 18459 were published in 2015 and ISO 18457 in 2016. ISO 18458, 'Biomimetics terminology, concepts and methodology ( $n=37)$; ISO 18459, 'Biomimetics - biomimetic structural optimization' $(n=15)$; ISO 18457, biomimetics - biomimetic materials, structures and components' $(n=7)$. $n$ refers to the number of articles citing the specific ISO standard. The number of overall identified articles is 43, as one article can cite one to all three standards

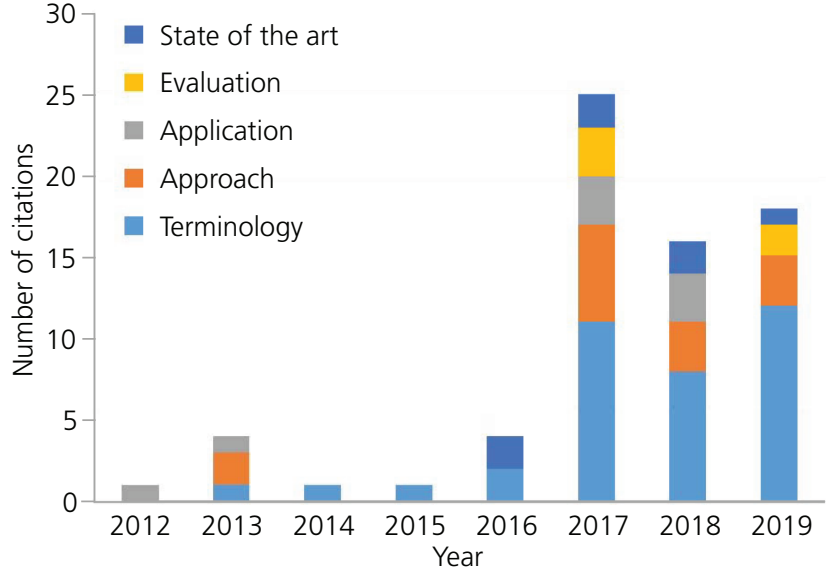

Figure 2. Number of citations of the different thematic categories of the ISO standards and VDI guidelines sorted by years. The ISO standards 18458 and 18459 were published in 2015 and ISO 18457 in 2016. Earlier citations refer to VDI guidelines published from 2012 onwards. The numbers of citations $(n)$ of the respective categories are as follows: terminology, $n=36$; approach, $n=14$; application, $n=8$; evaluation, $n=5$; and state of the art, $n=7$

\subsection{Patent databases}

Altogether only two different documents were identified that cite ISO standards or VDI guidelines referring to biomimetics.

\section{- DE102016204238A1, Fahrzeug mit einem Flächigen} Bauteil, ${ }^{66}$ uses the methods described in VDI 6224 Part 1, Part 2 and Part $3^{6,15,16}$ to optimise an automotive component by way of biomimetic structural optimisation. They cite the VDI guidelines to demonstrate the state of the art ('Ermittelter Stand der Technik').

- EP3543568 (A1) = US2019285182 (A1), Seal Ring, Sealing Arrangement, and Use of a Sealing Arrangement, ${ }^{67,68}$ cites ISO $18459^{9}$ as method that was used to optimise the structure, particularly according to the tensile triangles described therein.

No other patents citing a VDI guidelines or one of the other ISO standards were found.

\section{Discussion}

Learning from nature in the broadest sense is now common practice. A large number of publications in the scientific field and many patents bear witness to this. ${ }^{47,69}$ In addition, topics dealing with inventions of nature are becoming more well known through popular scientific reports. The number of publications dealing with biomimetics, biomimicry, bionics and biologically inspired design has risen sharply in recent years, even if the trend now seems to be slowing down. ${ }^{47}$ Nevertheless, it is fair to assume that there is a large number of works dealing with biomimetics in the broadest sense. An unspecific search using only the search term 'biomimetics' in the Web of Science database alone shows a number of documents of about 4107 (on 1 April 2020). The IEEE Xplore database shows a number of documents of about 10200 
(on 1 April 2020). Using Google Scholar, even a number of about 121000 hits for the keyword 'biomimetics' could be found (on 11 March 2020). A correspondingly unspecific search in Google Scholar from the paper by Lenau et al. ${ }^{47}$ with the search strings biomimicry OR biomimetics OR bionics OR bionic OR bioinspired OR "biologically inspired design" resulted in 346000 publications. The analysis of these authors also revealed that there is still a knowledge barrier between the application-oriented engineering sciences and the knowledge base in biology. ${ }^{47}$

In order to bridge this knowledge barrier and to provide a common basis for this growing number of scientists and engineers regarding terminology and methodology in the field of biomimetics, three international standards have been developed. Since 2016, ISO 18458 has provided a basis for terminology for the discipline of biomimetics, developed by international experts. In 2018, the standards ISO 18457 and ISO 18459 were published, which deal with biomimetic materials and biomimetic structural optimisation. This provides a basis for a common terminology and standardised methodological approaches to biomimetic developments for this growing field of research and development. Furthermore, several bilingual VDI guidelines on other biomimetic topics are available. The present study also wants to provide evidence of the extent to which this gap has been filled.

Since 2017, it has been possible to refer to these internationally developed definitions of biomimetics or the developed biomimetic methods. Nevertheless, there still seems to be a discrepancy between the work on biomimetics in a purely scientific sense and the application of biomimetics in a more technical sense. Only a comparatively small number of scientific publications since 2017 refer to the technical ISO standards. Forty-nine articles could be found in this analysis, which refer to one of the mentioned standards. The authors consider their research to be exhaustive, as they crosschecked the results of the different databases and made comparative analyses to be sure that each scientific paper is identified. For instance, the full-text and metadata search for 'ISO AND 18459' in IEEE Xplore led to 13 items. Only three of them were published after 2015, the year of the publication of the ISO standard. Screening the relevant three documents for the standard led to no citation. 'ISO' or ' 18459 ' was used in a different context and was therefore found. From the perspective of the ISO/TC 266 committee, in which the authors work actively, 59 citations in the scientific literature is an interesting starting point. As the authors do not have access to the number of sold or downloaded standards, it is difficult to measure the distribution of the standards according to the sold examples.

For comparison, in the period 2017-2020, about 700 documents are listed in Web of Science for the keyword 'biomimetics', and in IEEE Xplore, there are about 2200 documents. Lenau et al. ${ }^{47}$ name a number of over 2500 for a detailed analysis of the documents, which was carried out in Web of Science in 2018 for the keyword 'TS= (biomim* OR bionic* OR biologically inspired)'. Even under the cautious assumption that the time from the preparation of a publication to its publication may take 1 or even 2 years, the perception of ISO standards as an important instrument for quality assurance in the scientific and technical field could be better.

In order to have an indication of how great the perception of other ISO standards is, the citations are also given for ISO 14040, 'Environmental management - life cycle assessment - principles and framework'. This ISO standard is conceptually similar to ISO 18458 , since it also first provides a framework for a new topic area, and above all, definitions and a rough procedure of a lifecycle assessment are given. In Web of Science, 362 hits have been achieved over all years since publication in 2006, and in IEEE Xplore, there are only 16 hits for all years. If only the first four years after publication are taken into account, the number of citations of ISO 14040 and ISO 18458 are comparable. For Web of Science from 2007 to 2011, there are 59 hits, and for IEEE Xplore, three hits (queries on 11 March 2020). These hit rates are quite comparable with the 37 checked publications for ISO 18458. This indicates that ISO standards are noticed in the academic world only after a certain delay, even if they are topics that already have a certain legal basis, such as ISO 14040.

In the majority of the documents analysed in this paper, the standards on biomimetics are used to make use of the internationally agreed definitions presented therein and to use the same terminology. Besides, the standards help sort the variety of terms dealing with biomimetics in the broadest sense and to make it clear that they cannot be exchanged with each other. As (Ref. 47: p. 1) formulate: 'The terms are often used interchangeably but they are not synonymous and although similar they each have their special meaning which can be seen in the international ISO standard' ${ }^{47}$ Only one document discusses the method in ISO 18459 as not fully adequate for structural optimisation. ${ }^{40}$

The number of references to an ISO standard or VDI guideline in the published patents is very low. Here, the period until a patent is published is at least 18 months. One patent is from the end of 2019 and cites ISO 18459 from 2018 on the application of biomimetic structural optimisation. A patent from 2017 cites VDI 6224 Parts 1-3 to show the state of the art. These were published from 2012 to 2017 and indicate the state of the art for biomimetic structural optimisation. This may be the reason for the low number of citations of standards in patents. Although the state of the art can be indicated by a standard or guideline, a patent must, in order to have the necessary degree of novelty, go well beyond this state of the art in order to be patentable.

However, the number of citations in scientific publications or in patents may be only one indicator of the perception of ISO standards and their use. Also, surveys can provide information on how the ISO standards on biomimetics are known within companies. A Japanese study ${ }^{70}$ clearly shows that among 276 respondents, about $40 \%$ stated that they are familiar with the definitions of biomimetics in the ISO standards. The higher number of citations of the ISO standards indicates that an international joint effort to develop technical rules, reports or 
standards has a greater impact, at least in the field of biomimetics, than individual national initiatives, even though these may be available internationally, as the VDI guidelines have been for years.

In view of the high proportion of application-oriented research carried out in biomimetics, it is all the more surprising that the research community is not familiar with the relevant standards. This leads to the question how the standards are communicated and known and how the awareness for using the standards could be risen. Additionally, the relevance and importance of the standards for the scientific community need to be reflected or even analysed in more detail. This is one of the tasks of ISO/TC 266. The results of such an analysis and the results presented in this paper can help motivate others to join the work and to help improve the standards - for example, by adding additional topics that should be addressed. Standardisation work is a common effort, and the more experts are willing to join the discussions, the more appropriate the standards will be.

\section{Conclusion}

It can be stated that there is a certain perception of standards and technical rules in the field of biomimetics. If they are cited, however, this is essentially done in order to use the definitions laid down in the standards. To a lesser extent, the standards are cited to use a defined methodology. This is, apart from establishing definitions, one of the original tasks of standardisation in the sense of the sentence quoted at the beginning: 'what is the best way of doing this?' In this context, the methods of biomimetic optimisation are primarily used.

Nevertheless, the overall perception of this standardisation work could be clearer and more indicators should be used to evaluate the perception. In the academic environment, it is still not sufficiently recognised that standards are also of great importance for quality assurance in scientific work. It is essential to continue to emphasise the importance of international standardisation through appropriate public relations work. This paper is intended to make a contribution to this and draw attention in the academic field to international standards on biomimetics.

\section{Acknowledgements}

The authors thank Norbert Hoeller for providing valuable feedback on the original manuscript. They would also particularly like to thank Ms Dipl.-Biol. Gertrud Hötten, patent scout of Westfälische Hochschule, who conducted the patent search for them.

\section{REFERENCES}

1. ISO (International Organization for Standardization) (2020) Benefits of Standards. ISO, Geneva, Switzerland. See https://www.iso.org/ benefits-of-standards.html (accessed 18/02/2020).

2. DIN (Deutsches Institut für Normung) (2020) Rechtsverbindlichkeit von Normen. DIN, Berlin, Germany (in German). See https://www. din.de/de/ueber-normen-und-standards/normen-und-recht/ rechtsverbindlichkeit-durch-normen (accessed 18/02/2020).
3. ISO Technical Committee 266 (2018) Business Plan - ISO/TC 266 Biomimetics. ISO, Geneva, Switzerland.

4. VDI (Verein Deutscher Ingenieure e.V.) (2019). VDI 6220 Blatt 1: Entwurf/draft: Biomimetics - fundamentals, conception and strategy. Beuth-Verlag, Berlin, Germany (in German).

5. VDI (2013) VDI 6223 Blatt 1: Biomimetics - Biomimetic materials, structures and components. Beuth-Verlag, Berlin, Germany.

6. VDI (2012) VDI 6224 Blatt 2: Biomimetic optimization - application of biological growth laws for the structure-mechanical optimization of technical components. Beuth-Verlag, Berlin, Germany.

7. ISO (2015) ISO 18458:2015: Biomimetics - terminology, concepts and methodology. ISO, Geneva, Switzerland.

8. ISO (2016) ISO 18457:2016: Biomimetics - biomimetic materials, structures and components. ISO, Geneva, Switzerland.

9. ISO (2015) ISO 18459:2015: Biomimetics - biomimetic structural optimization. ISO, Geneva, Switzerland.

10. Rehme O, Beismann $\mathrm{H}$ and Schmitt M (2018) Bionik - Normung im Fokus. DIN-Normenausschuss Materialprüfung (NMP). Drei DINNormen zum Thema erschienen. DIN-Mitteilungen Zeitschrift für Deutsche, Europäische und Internationale Normung 2018(9): 20-23 (in German).

11. Hoeller N and Salustri FA (2016) Advancing biomimetic materials through ISO standards. Bioinspired, Biomimetic and Nanobiomaterials 5(4): 171-175.

12. VDI (2012) VDI 6220 Blatt 1: Biomimetics - conception and strategy differences between biomimetic and conventional methods/products. Beuth-Verlag, Berlin, Germany.

13. VDI (2013) VDI 6221 Blatt 1: Biomimetics - biomimetic surfaces. Beuth-Verlag, Berlin, Germany.

14. VDI (2013) VDI 6222 Blatt 1: Biomimetics - biomimetic robots. Beuth-Verlag, Berlin, Germany.

15. VDI (2012) VDI 6224 Blatt 1: Biomimetic optimization - application of evolutionary algorithms. Beuth-Verlag, Berlin, Germany.

16. VDI (2017) VDI 6224 Blatt 3: Biomimetics - integrated product development process for biomimetic optimisation. Beuth-Verlag, Berlin, Germany.

17. VDI (2012) VDI 6225 Blatt 1: Biomimetics - Biomimetic information processing. Beuth-Verlag, Berlin, Germany.

18. VDI (2015) VDI 6226 Blatt 1: Biomimetics - architecture, civil engineering, industrial design - basic principles. Beuth-Verlag, Berlin, Germany.

19. Fremerey M, Gorb S, Heepe L et al. (2012) Shifting allometry: combination of macroscopic engineering with microscopic biomimetics allows realization of new robot functions in meso dimension. In Robotik 2012: 7th German Conference on Robotics, München (VDE Verband der Elektrotechnik Elektronik Informationstechnik e.V. (ed.)). IEEE, Piscataway, NJ, USA, pp. $165-170$

20. Vagts S and Schlattmann J (2013) Entwicklung eines horizontalen und vertikalen Handlungsprozesses in der interdisziplinären Produktentwicklung - Heli-Act-Methode. In Stuttgarter Symposium für Produktentwicklung 2013: Stuttgart, 20. Juni 2013 (Spath D (ed.)). Fraunhofer Verlag, Stuttgart, Germany, pp. 1-10 (in German).

21. Witte H, Fremerey M, Weyrich S et al. (2013) Biomechatronics is not just biomimetics. In Proceedings of the 9th International Workshop on Robot Motion and Control (Institute of Electrical and Electronics Engineers (ed.)). Institute of Electrical and Electronics Engineers, New York, NY, USA, pp. 74-79.

22. Jacobs S (2014) Biomimetics: a simple foundation will lead to new insight about process. International Journal of Design \& Nature and Ecodynamics 9(2): 83-94.

23. Nakajima K, Tausch K, Maurer P, Paulo L and Schwarz O (2015) Der Bohrmechanismus der Hautflügler und seine Anwendung in der orthopädischen Chirurgie. In Bionik: Patente aus der Natur: Tagungsbeiträge 7. Bionik-Kongress; Hochschule Bremen 24.-25. 
Bioinspired, Biomimetic and Nanobiomaterials Volume 10 Issue 1
Perception and role of standards in the

world of biomimetics

Wanieck and Beismann
Oktober 2014; Innovations- und Nachhaltigkeitspotenziale für Technologieanwendungen (Kesel AB (ed.)). Bionik-InnovationsCentrum, Bremen, Germany, vol. 7, pp. 93-104 (in German).

24. Caputo ET, Waechter PR and Tucker SE (2016) Simulating HIV-1 Protease Mutations for Conferred Drug Resistance. Worcester Polytechnic Institute, Worcester, MA, USA.

25. Hosoda N (2016) Eco-friendly adhesion technology learning from nature. Oleoscience 16(12): 579-585 (in Japanese).

26. Bianciardi A, Credi C, Levi M, Rosa F and Zecca A (2017) Biomimicry thinking: methodological improvements and practical implementation. Bioinspired, Biomimetic and Nanobiomaterials 6(2): 87-101.

27. Dicks H (2017) Environmental ethics and biomimetic ethics: nature as object of ethics and nature as source of ethics. Journal of Agricultural and Environmental Ethics 30(2): 255-274.

28. Drack M, Limpinsel M, de Bruyn G, Nebelsick JH and Betz O (2017) Towards a theoretical clarification of biomimetics using conceptual tools from engineering design. Bioinspiration \& Biomimetics 13(1): article 16007

29. Fayemi PE, Wanieck K, Zollfrank C, Maranzana N and Aoussat A (2017) Biomimetics: process, tools and practice. Bioinspiration \& Biomimetics 12(1): article 11002.

30. Fayemi PE (2017) Innovation par la Conception Bio-inspirée Proposition d'un Modèle Structurant les Méthodes Biomimétiques et Formalisation d'un Outil de Transfert de Connaissances. Doctoral thesis, Arts et Métiers ParisTech, Paris, France (in French).

31. Kamps T, Gralow M, Schlick G and Reinhart G (2017) Systematic biomimetic part design for additive manufacturing. Procedia CIRP 65: 259-266.

32. Le NT, Warschat J and Farrenkopf T (2017) An early-biologisation process to improve the acceptance of biomimetics in organizations. In Advanced Computational Methods for Knowledge Engineering (Le NT, van Do T, Nguyen NT and Thi H (eds)). Springer, Cham Switzerland, pp. 175-183.

33. Marry AK, Goncalves AP, Cossette BJ and William ME (2017) Highthroughput Maturation of Engineered Human Skeletal Muscle Tissue. Worcester Polytechnic Institute, Worcester, MA, USA.

34. Rowland R (2017) Biomimicry step-by-step. Bioinspired, Biomimetic and Nanobiomaterials 6(2): 102-112.

35. Speck O, Speck D, Horn R, Gantner J and Sedlbauer KP (2017) Biomimetic bio-inspired biomorph sustainable? An attempt to classify and clarify biology-derived technical developments. Bioinspiration \& Biomimetics 12(1): article 11004.

36. Wanieck K, Fayemi PE, Maranzana N, Zollfrank C and Jacobs S (2017) Biomimetics and its tools. Bioinspired, Biomimetic and Nanobiomaterials 6(2): 53-66.

37. Heinrichs A, Frank P, Siegel D and Frank M (2017) Bionische Entwicklung einer additiv gefertigten A-Säulen-Verstärkung. Lightweight Design 10(4): 74-81 (in German).

38. Kunz PM (2017) Von der Natur inspiriert. Materialien aus der Chemischen Industrie in bionisch entwickelten Produkten und Verfahren. CHEManager 26(10): 12 (in German).

39. Shatokha V, Stalinskiy D, Coole T et al. (2017) Environmentally Sustainable Industrial Development. Academic Council of the National Metallurgical Academy of Ukraine, Dnipro, Ukraine.

40. Zhou M and Sigmund O (2017) On fully stressed design and p-norm measures in structural optimization. Structural and Multidisciplinary Optimization 56(3): 731-736.

41. Bhasin D and McAdams D (2018) The characterization of biological organization, abstraction, and novelty in biomimetic design. Designs 2(4): article 54.

42. Caillieux L, Graeff E, Gazo C and Maranzana N (2018) Proposition d'une methodologie innovative de resolution de problemes incluant de la bioinspiration. Proceedings of Confere'18. Budapest, Hungary (in French).

43. Fayemi PE, Gilles M and Gazo C (2018) Innovative technical creativity methodology for bio-inspired design. In Automated Invention for
Smart Industries: 18th International TRIZ Future Conference, TFC 2018, Strasbourg, France, October 29-31, 2018, Proceedings (Cavallucci D, De Guio R and Koziołek S (eds)). Springer, Cham, Switzerland, pp. 253-265

44. Graeff E, Maranzana N and Aoussat A (2018) Role of biologists in biomimetic design processes: preliminary results. In $D S 92$ : Proceedings of the DESIGN 2018 15th International Design Conference (Marjanović D, Štorga M, Škec S, Bojčetić N and Pavković N (eds)). The Design Society, Glasgow, UK, pp. $1149-1160$

45. Hamilton R, Godding S and Gray S (2018) Mechanical Stimulation of Engineered Muscle. Worcester Polytechnic Institute, Worcester, MA, USA.

46. Kanda GB, Souza RDO and de Held MSB (2018) Matriz morfológica e biomimética: geração de alternativas em design. Projetica Revista Cientifica de Design 9(1): 53-68 (in Portuguese).

47. Lenau TA, Metze AL and Hesselberg T (2018) Paradigms for biologically inspired design. In Bioinspiration, Biomimetics, and Bioreplication VIII: 5-7 March 2018, Denver, Colorado, United States (Lakhtakia A (ed.)). SPIE, Bellingham, WA, USA, paper no. 1059302.

48. Letard A, Maranzana N, Raskin K and Aoussat A (2018) Design et biomimetisme: quel role pour le designer? Proceedings of Confere'18, Budapest, Hungary (in French).

49. Nosonovsky M (2018) Cultural implications of biomimetics: changing the perception of living and non-living. MOJ Applied Bionics and Biomechanics 2(4): 230-236.

50. Stylianidis E (2018) Outil d'Aide à la Décision pour la Conception de Façades Biomimétiques. Master's thesis, Liège Université, Liège, Belgium.

51. Bartz M, Gößling R, Remus R and Bender B (2018) Development of a bioinspired approach for the design of kinematic chains. In $D S 92$ : Proceedings of the DESIGN 2018 15th International Design Conference (Marjanović D, Štorga M, Škec S, Bojčetić N and Pavković N (eds)). The Design Society, Glasgow, UK, pp. 975-984.

52. Byrne G, Dimitrov D, Monostori L et al. (2018) Biologicalisation: biological transformation in manufacturing. CIRP Journal of Manufacturing Science and Technology 21: 1-32.

53. Voelkl H and Wartzack S (2018) Design for composites: tailor-made, bio-inspired topology optimization for fiber-reinforced plastics. In $D S$ 92: Proceedings of the DESIGN 2018 15th International Design Conference (Marjanović D, Štorga M, Škec S, Bojčetić N and Pavković N (eds)). The Design Society, Glasgow, UK, pp. 499-510.

54. Adriaens D (2019) Evomimetics: the biomimetic design thinking 2.0. Proceedings of SPIE - Bioinspiration, Biomimetics, and Bioreplication IX (Lakhtakia A, Martín-Palma RJ and Knez M (eds)). SPIE, Denver, CO, USA, paper no. 1096509.

55. Bensaude-Vincent B (2019) Bio-informed emerging technologies and their relation to the sustainability aims of biomimicry. Environmental Values 28(5): 551-571.

56. Chirazi J, Wanieck K, Fayemi PE, Zollfrank C and Jacobs S (2019) What do we learn from good practices of biologically inspired design in innovation? Applied Sciences 9(4): article 650.

57. Graeff E, Gras M, Piroux R et al. (2019) First step to combine bioinspiration and frugal innovation: application to a container's village. In Research into Design for a Connected World (Chakrabarti A (ed.)). Springer, Singapore, pp. 461-472.

58. Graeff E, Maranzana N and Aoussat A (2019) Biomimetics, where are the biologists? Journal of Engineering Design 201(1): 1-22.

59. Graeff E, Maranzana N and Aoussat A (2019) Engineers' and biologists' roles during biomimetic design processes: towards a methodological symbiosis. In DS 94: Proceedings of the Design Society: 22nd International Conference on Engineering Design (ICED 19) (Wartzack S, Schleich B and Gon (eds)). The Design Society, Glasgow, UK, pp. 319-328. 
Bioinspired, Biomimetic and Nanobiomaterials Volume 10 Issue 1
Perception and role of standards in the

world of biomimetics

Wanieck and Beismann
60. Kamili L (2019) Biomimétisme et bio-inspiration: nouvelles techniques, nouvelles éthiques? Techniques \& Culture, 15 January (in French). See http://journals.openedition.org/tc/9299 (accessed 25/02/2021)

61. Kaminski R, Speck T and Speck O (2019) Biomimetic 3D printed lightweight constructions: a comparison of profiles with various geometries for efficient material usage inspired by square-shaped plant stems. Bioinspiration \& Biomimetics 14(4): article 46007.

62. Saratti CM, Rocca GT and Krejci I (2019) The potential of threedimensional printing technologies to unlock the development of new 'bio-inspired' dental materials: an overview and research roadmap. Journal of Prosthodontic Research 63(2): 131-139.

63. Speck O and Speck T (2019) An overview of bioinspired and biomimetic self-repairing materials. Biomimetics 4(26): 1-34.

64. Svendsen N and Lenau TA (2019) How does biologically inspired design cope with multi-functionality? In DS 94: Proceedings of the Design Society: 22nd International Conference on Engineering
Design (ICED 19) (Wartzack S, Schleich B and Gon (eds)). The Design Society, Glasgow, UK, pp. 349-358.

65. Terrier P, Glaus M and Raufflet E (2019) BiomiMETRIC assistance tool: a quantitative performance tool for biomimetic design. Biomimetics 4(3): article 49.

66. Fischer D and Madlener R (2016) Fahrzeug mit einem Flächigen Bauteil, German Patent DE102016204238A1, Mar. (in German).

67. Möller S, Fietz R, Groesch M, Jaeckel J and Barillas G (2018) Dichtring, Dichtungsanordnung und Verwendung einer Dichtungsanordnung, German Patent EP3543568 (A1), Sep. (in German).

68. Möller S, Fietz R, Groesch M, Jaeckel J and Barillas G (2019) Seal Ring, Sealing Arrangement, and Use of a Sealing Arrangement, US Patent, US2019285182 (A1), Sep.

69. Lepora NF, Verschure P and Prescott TJ (2013) The state of the art in biomimetics. Bioinspiration \& Biomimetics 8(1): article 13001.

70. Kohsaka R, Fujihira $Y$ and Uchiyama $Y$ (2019) Biomimetics for business? Industry perceptions and patent application. Journal of Science and Technology Policy Management 10(3): 597-616.

\section{How can you contribute?}

To discuss this paper, please submit up to 500 words to the journal office at journals@ice.org.uk. Your contribution will be forwarded to the author(s) for a reply and, if considered appropriate by the editor-in-chief, it will be published as a discussion in a future issue of the journal.

ICE Science journals rely entirely on contributions from the field of materials science and engineering. Information about how to submit your paper online is available at www.icevirtuallibrary.com/page/authors, where you will also find detailed author guidelines. 